\title{
Coulisses
}

Revue de théâtre

25 | Hiver 2002

Varia

\section{Une revue qui se confirme : Coulisses}

\section{(2) OpenEdition}

1 Journals

Édition électronique

URL : http://journals.openedition.org/coulisses/6102

DOI : $10.4000 /$ coulisses. 6102

ISSN : 2546-9460

\section{Éditeur}

Presses universitaires de Franche-Comté

\section{Édition imprimée}

Date de publication : 1 janvier 2002

Pagination : 121

ISBN : 2-84627-052-X

ISSN : $1150-594 X$

\section{Référence électronique}

"Une revue qui se confirme: Coulisses », Coulisses [En ligne], 25 | Hiver 2002, mis en ligne le 24 octobre 2019, consulté le 15 novembre 2019. URL : http://journals.openedition.org/coulisses/6102 ; DOI : 10.4000/coulisses.6102

Ce document a été généré automatiquement le 15 novembre 2019.

Coulisses 


\section{Une revue qui se confirme : Coulisses}

Coulisses s'est doté d'un comité de lecture plus étoffé.

\section{Deux conventions ont été signées...}

Convention entre le T.U.F.C. et les P.U.F.C. : À la demande de l'université, une convention a été signée entre le T.U.F.C. et les P.U.F.C. officialisant les relations existantes: Coulisses est une série de la collection des Annales littéraires, publiées par les P.U.F.C.

Convention entre le T.U.F.C. et l'Association pour la recherche claudélienne pilotée par le centre Jacques-Petit : Pour un dossier d'emploi jeune en partenariat avec le G.R.E.L.I.S., Sébastien Jacquot se chargera pour $1 / 5^{\mathrm{e}}$ de temps de la mise en page de Coulisses et du site internet du T.U.F.C.

\section{Politique éditoriale}

\section{Publication d'œuvres inédites}

Jusqu'à ce jour, les textes étaient en rapport direct avec les activités du T.U.F.C et du centre Jacques-Petit (Le Radeau de la Méduse d'Egon Wolf (Chili), Fin de siècle sur l'Ile de Alezandro Finzi (Argentine), Incertitudes de la mécanique quantique (...) d'Armand Gatti. Mais des auteurs envoient des pièces de théâtre et veulent être édités dans Coulisses, quelle politique adopter?

- Problèmes vis-à-vis des éditeurs privés (concurrence déloyale si Coulisses édite des textes)

- Il existe des éditions régionales spécialisées pour l'édition de textes de théâtre

- La publication d'inédits n'est possible que s'il y a un rapport avec les actions du T.U. et du centre Jacques-Petit.

Projets : Compte rendu de la résidence-création d'Armand Gatti, décembre 2002 Choses d'Anoch Levine, traduction d'Ilana Zinguer, université d'Haïfa. 


\section{Site internet}

«Les Solitaires Intempestifs» sont d'accord pour héberger Coulisses sur leur site internet. Cela permettrait de s'affirmer un peu plus dans l'espace théatral local et national. Leur site est en effet très fréquenté.

\section{Relations avec les éditeurs de théâtre}

Il paraît important de connaître et de faire connaître des éditeurs régionaux de théâtre. Dans cette perspective, un dossier sera consacré aux deux éditeurs régionaux de théâtre dans Coulisses $n^{\circ} 26$, sous la responsabilité d'Elyette Bogliolo

\section{Des nouvelles des textes que Coulisses a publiés...}

C'est grâce à Carole Michel que Coulisses entretient des relations suivies avec Egon Wolff. Le Radeau de la Méduse a été créé à Paris au festival Ibéral.

Alejandro Finzi nous a informé que Fin de siècle sur l'île, cahier de Coulisses $n^{\circ} 1$ a été créé dans le cadre du Festival Ibéral à Paris par la compagnie Luis Jaime-Cortez en 2001. Le texte a obtenu le $2^{\mathrm{e}}$ prix national de littérature dramatique pour la période 1996-2000. 